\title{
CAPTAÇÃO, TRATAMENTO E REÚSO DE ÁGUAS CINZAS E PLUVIAIS EM RESIDÊNCIA UNIFAMILIAR
}

\author{
Otávio Pinetti Monteiro ${ }^{1}$ \\ Gemael Barbosa Lima²
}

\begin{abstract}
RESUMO
O trabalho tem como objetivo apresentar uma revisão bibliográfica, cujo assunto é o reaproveitamento de água pela chuva, assim como o reúso de águas cinzas em residência unifamiliar. Para isso, a metodologia constitui em uma busca de informações em livros, revistas, artigos, dissertações de mestrado e em teses de doutorado. Para reaproveitar de forma consciente, serão apresentadas formas de captar a água advinda de uma residência, seja da chuva que cai sobre as calhas ou a usada nos métodos de captação nas pias da cozinha e/ou tanques de áreas de serviços que receberão o tratamento necessário e serão reutilizadas. Esses tratamentos atuam de forma eficiente e proporcionam o uso dessa água para fins menos nobres o que torna o consumo mais racional e econômico, cooperando para a manutenção dos recursos ambientais.
\end{abstract}

Palavras-chave: Água; Reaproveitamento; Captação; Tratamento; Residência.

\section{ABSTRACT}

The objective of this work is to present a bibliographical review, whose subject is the reuse of water by rain, as well as the reuse of gray water in a single-family dwelling. For this, the methodology consisted of searching for information in books, journals, articles, master's dissertations and in doctoral theses. To reuse consciously, you will be presented ways to capture the water coming from a residence, either from the rain that falls on the gutters or the one used in the picking methods in the kitchen sinks and / or tanks of service areas that will receive the necessary treatment and will be reused. These treatments work efficiently and provide the use of this water for less noble purposes which makes consumption more rational and economical, cooperating for the maintenance of environmental resources.

Keywords: Water; Reuse; Captation; Treatment; Residence.

\footnotetext{
${ }^{1}$ Graduando em Engenharia Civil do Centro Universitário do Espírito Santo - UNESC

${ }^{2}$ Mestre em Engenharia Ambiental, professor do UNESC
} 


\section{INTRODUÇÃO}

Conforme afirma Zampieron (2005), a água tornou-se símbolo comum da humanidade, valorizada em todas as religiões e culturas, também um símbolo da igualdade social, pois a crise da água é, acima de tudo, de distribuição, recursos e não somente em sua escassez absoluta. Com o objetivo claro de reduzir o consumo de água, através de novas tecnologias, deu-se início ao desenvolvimento de diversos programas de uso racional.

Tais problemas associados corroboram para a discussão da viabilidade de se fazer o uso de água pluvial e águas cinzas para atividades fundamentais em uma residência. Essa possibilidade de reúso certamente resultará na diminuição do consumo de água tratada que é fornecida pelas companhias de saneamento, além disso haverá um decréscimo na demanda dos custos com o uso de água potável e na redução dos riscos provenientes de enchentes em períodos de chuvas intensas.

Portanto, a pesquisa abordada tem por objetivo demonstrar como é feito o reúso da água vinda da chuva juntamente com a reutilização da água cinza em uma residência unifamiliar, a partir da apresentação de estudo de caso. Toda a base do trabalho foi encontrada através de informações em livros, revistas, artigos e dissertações de mestrados, em que os autores além de pesquisadores da área, utilizaram-se de pesquisas laboratoriais e acadêmicas para embasarem seus resultados.

Apesar de a água ser um recurso renovável, a sua oferta não atende à demanda que com o passar do tempo vem aumentando substantivamente. Com isso sempre existirá um déficit, que cada vez está mais acentuado pelo uso irracional e desperdícios diversos. Assim, se torna cada vez mais necessário estabelecer uma nova relação entre o homem e a água, para isso estão sendo ampliadas as opções do uso racional e somando a esse fator, alternativas de se aproveitar de forma eficiente, seja através de captação e tratamento de forma simples como abordado no trabalho ou por métodos mais específicos que ainda não são bem recebidos pela população por ter o preço de investimento muito alto. 


\section{REFERENCIAL TEÓRICO}

[...] Aliada à mencionada capacidade de dissolução, a água atua como meio de transporte - em escoamento superficial e subterrâneo - permitindo que as características de um mesmo curso d'água alterem-se temporal e espacialmente. (LIBÂNIO, 2010, p.15)

A potabilização das águas naturais para fins de consumo humano tem como função essencial adequar a água bruta aos limites físicos, químicos, biológicos e radioativos estabelecidos pela Portaria 2914, tornado o efluente da estação incapaz de transmitir qualquer maléfico à população abastecida.

[...] O tratamento de água consiste na remoção de partículas suspensas e coloidais, matéria orgânica, microrganismos e outras substâncias deletérias à saúde humana, porventura presentes nas águas naturais, aos menores custos de implantação, operação e manutenção, e gerando o menor impacto ambiental às áreas circunvizinhas. (LIBÂNIO, 2010, p.135).

\subsection{USO DA ÁGUA NO ÂMBITO DA CONSTRUÇÃO CIVIL}

Segundo Mayok (2009), existem outras normas, tais como a NBR 7229/1993, que dispõe do dimensionamento do sistema de águas servidas; e as diretrizes de conservação e reúso da água em edificações elaborado pelo Sindicato da Construção Civil (Sinduscon), que apresenta diversas maneiras de reutilizar a água, até mesmo na lavagem de agregados para o uso na construção civil.

Conforme Sickermann (2005) citado por PROSAB, 2006 por ser um recurso de extrema importância para a construção, a água é usada em todas as etapas de uma obra, da produção do concreto até para suprir as necessidades básicas dos operários - e sua escassez já é sentida em canteiros de obras em diferentes locais do país.

De acordo com o vice-presidente do Sindicato da Construção (Sinduscon - MG) Geraldo Jardim Linhares Júnio, embora a situação ainda não seja grave, construtoras já têm optado, há algum tempo, pela substituição de métodos convencionais por métodos de construção seca, de forma a criar certa independência da água (MARIANE, 2014).

\subsection{USOS MÚLTIPLOS DA ÁGUA}

Baseando-se nas pesquisas de Tomaz (2005) no que diz respeito em se reaproveitar a água da chuva, o uso de medidas e técnicas se mostra de forma excelente para evitar e sanar os problemas acerca da falta de água potável, mesmo 
sem leis que regulam seu uso. A utilização de métodos adequados e o uso alternado com as águas advindas de esgotos domésticos, seria uma forma inteligente de se conservar a água para fins nobres.

Conforme indica Caubet (2006), representante das Organizações não Governamentais (ONG's) no Conselho Nacional de Recursos Hídricos (CNRH), mesmo que o Código das Águas (Decreto Federal no 24.643, de 10/07/1934) apresente prioridade absoluta do uso da água para as necessidades básicas dos seres humanos (dessedentação e usos domésticos), a maior retirada acontece na área da agricultura $(62,7 \%)$, em seguida se dá através do consumo humano $(17,9 \%)$ e o uso industrial (14\%) e, por fim, no consumo animal $(5,4 \%)$, como mostra a Figura 01.

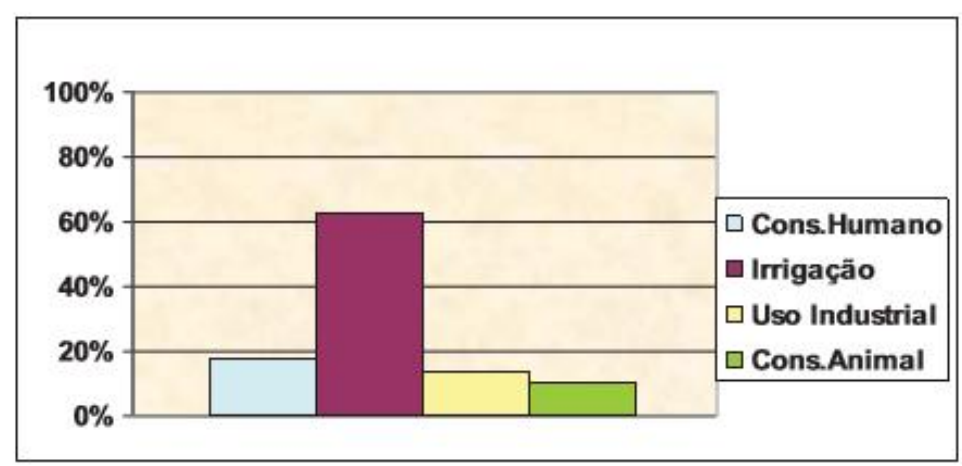

Figura 01-Consumo de água por atividade no Brasil. Fonte: ANA (2002) citado por Manual FIESP/CIESP (2006).

\subsubsection{Usos da água não potável}

Estudos feitos no Brasil e no exterior mostram que em uma residência, grande parte do consumo de água concentra-se nos banhos, na descarga dos vasos sanitários, na pia da cozinha e na lavagem de roupas. Em média, 40\% do total de água consumida em uma residência são para o uso de forma não potável. (GONÇALVES, 2009).

A necessidade de analisar a quantidade de água distribuída para atender as atividades básicas de consumo e higiene é motivo de discussão entre vários autores, como podemos analisar pela Figura 02. Uma definição proposta por Peter Gleick, que consta no Basic Water Requirement (BWR), é de que 50 L/hab/dia é uma quantidade suficiente para suprir estas necessidades (BIO, 2002). 


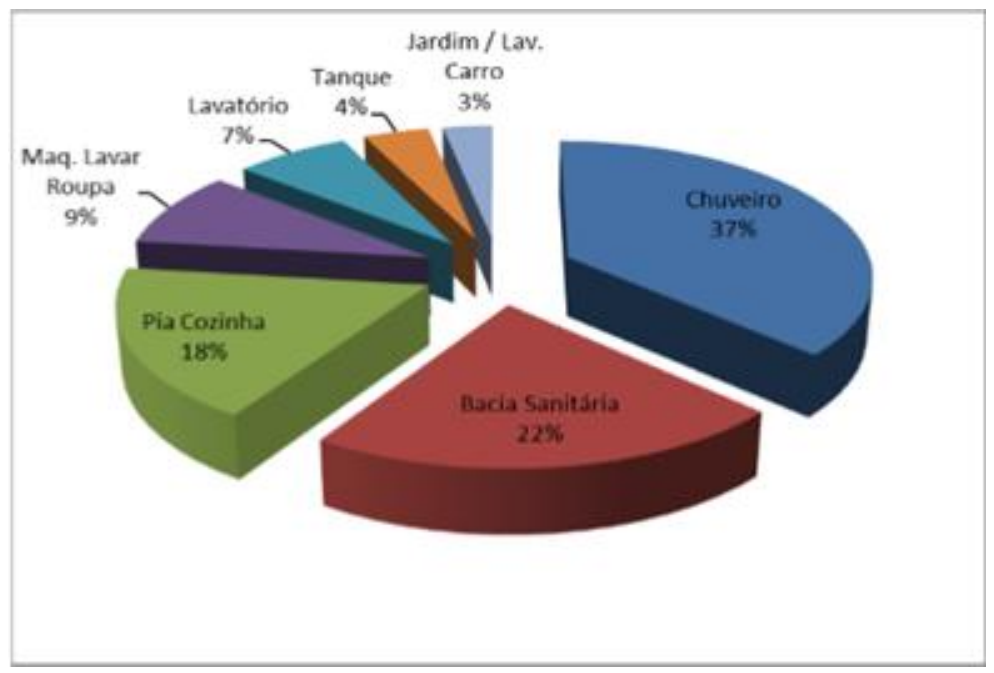

Figura 02 - Distribuição do consumo de água nas residências por cada aparelho Fonte: Adaptado de Martins e Memelli (2011)

\subsubsection{Usos da água potável}

A água potável é toda água própria para o consumo. Sendo um líquido incolor, inodoro, insípido e insosso, essencial para a sobrevivência humana, como afirma Hespanhol (2002).

\subsubsection{Tratamento}

Não é primordial que a água existente no manancial apresente todos os indicativos adequados para o consumo, pois conforme Braga (2005) há maneiras de alterar suas características para torná-la compatível com as exigências de saúde pública.

Ainda de acordo com Braga (2005), os principais métodos de tratamento da água são: decantação, floculação, filtração, desinfecção, remoção da dureza, aeração, remoção de ferro e manganês, remoção de sabor e odor, controle de corrosão e fluoretação, que são sempre interligados e que a falta, de tratamento adequado de alguns desses itens pode alterar a qualidade final da água.

\section{MATERIAIS E MÉTODOS}

A metodologia desse artigo consistiu em pesquisa bibliográfica em livros, revistas científicas, teses de doutorado e dissertações de mestrado. A revisão limitou- 
se às formas de se captar e aproveitar a água pluvial, além disso, foi discutido ainda acerca do aproveitamento de águas cinzas. O foco deste trabalho foi versar sobre as supracitadas técnicas no âmbito de residência unifamiliar.

Para embasar melhor a revisão bibliográfica proposta nesse artigo, foi apresentado, estudo de caso por Oliveira (2005) no município de Palhoça, situado a $15 \mathrm{~km}$ de Florianópolis, no estado de Santa Catarina. Após a apresentação dos resultados da pesquisa de Oliveira (2005), a discussão foi realizada trazendo outros trabalhos similares.

Nas seções a seguir serão apresentados a área de estudo e o objetivo, bem como as características da residência, entre outros aspectos do estudo de caso escolhido para citação desse artigo.

\section{1 ÁREA DE ESTUDO}

O município escolhido para se implantar o projeto foi Palhoça, localizada a 15 km de Florianópolis entre o litoral e a Serra do Mar, no meridiano 4840'04" de longitude oeste e paralelo $28^{\circ} 38^{\prime} 43^{\prime \prime}$ de latitude sul. Possui uma área de 323 km², sendo que $73,0 \%$ do território é considerado Área de Preservação Permanente. A população do município, segundo o IBGE (2004), é de 113.312 habitantes, conforme (PALHOÇA, 2004). Palhoça segundo Setti (1994) está a três metros acima do nível do mar, em uma planície litorânea com mangues, restingas e maciços rochosos da Serra do Mar. O clima, de acordo com o autor, é úmido com temperatura média de 25ㄷ․ A precipitação média anual, de 1969 a 2002, segundo CLIMERH/EPAGRI é de $1706 \mathrm{~mm}$.

\subsection{OBJETO DE ESTUDO}

O estudo foi baseado em duas residências distintas e localizadas a uma distância de $2 \mathrm{~km}$ entre si. A residência 01 possui área de $131,36 \mathrm{~m}^{2}$ e a residência 02 possui área de 143,27 $\mathrm{m}^{2}$. Na residência 01, os pontos de consumo se localizam no banheiro, na área de serviço e na cozinha. O banheiro é constituído de um chuveiro, um lavatório, um vaso sanitário com descarga do tipo válvula. Na cozinha, há uma torneira na pia. $\mathrm{Na}$ área de serviço, há uma máquina de lavar roupas que utiliza 100 litros de água por ciclo e uma torneira situada no tanque. Já na residência 02 , os pontos de 
consumo de água estão situados em três banheiros, na cozinha e na área de serviço. Nos três banheiros há dois chuveiros, três torneiras para lavatório, sendo duas com misturadores e três descargas sanitárias. Na cozinha, há uma torneira com misturador e na área de serviço há uma máquina de lavar roupas com consumo de 801 por ciclo e uma torneira no tanque. Em ambas as residências praticamente não se utiliza a água potável para lavar calçadas, carros ou regar jardim. O aproveitamento da água utilizada pela lavadora de roupas já acontece em ambas as residências, armazenando-a em tanques para posterior reaproveitamento nas calçadas e nos jardins.

\subsection{SISTEMA DE COLETA E ARMAZENAMENTO DA ÁGUA DA CHUVA E DE REÚSO}

\subsubsection{Determinação das áreas da cobertura}

Para armazenar a água vinda da chuva faz-se necessário o levantamento das áreas de telhado de ambas as residências. A determinação destas áreas se fez através de uma vasta análise das plantas da cobertura das residências propostas sendo as mesmas importantes na captação.

\subsubsection{Coleta de água dos telhados}

As águas pluviais são captadas por calhas e levadas até o reservatório inferior através de condutores verticais, dimensionados de acordo com a NBR 10844 (ABNT, 1989). Esta norma trata das instalações prediais de águas pluviais.

\subsubsection{Reservatório para captação da água pluvial}

Para se chegar ao volume do reservatório que armazena a água proveniente da chuva, foi analisado as áreas de contribuição da cobertura das residências, no consumo diário de água por habitante, na precipitação da região e no coeficiente de aproveitamento da água de chuva. Este coeficiente mostra o percentual que é armazenada, pois o restante é utilizado para a limpeza do telhado, das calhas e 
tubulações e para a evaporação. Para este estudo, adotar-se-á que $80 \%$ da água que cai sobre o telhado será coletada.

Em cada residência existirá dois reservatórios, um inferior que fará 0 armazenamento da água de chuva coletada e o superior que será usado para distribuir as águas para o consumo. O inferior será de fibra de vidro enterrado no terreno. $O$ descarte da primeira água de chuva será efetuado ao longo da tubulação localizado antes da entrada da água no reservatório. A primeira chuva fica retida neste tubo evitando que grande parte das impurezas chegue ao reservatório. Para a retenção de resíduos maiores será instalada na saída das calhas uma grelha flexível em PVC. Na extremidade da tubulação de entrada de água no reservatório, serão instalados uma redução e um joelho de $90^{\circ}$ com diâmetro maior que a tubulação de entrada. $O$ aumento de área diminui o impacto da água de chuva coletada com o fundo do reservatório, evitando-se assim a agitação de partículas depositadas, (Figura 03).

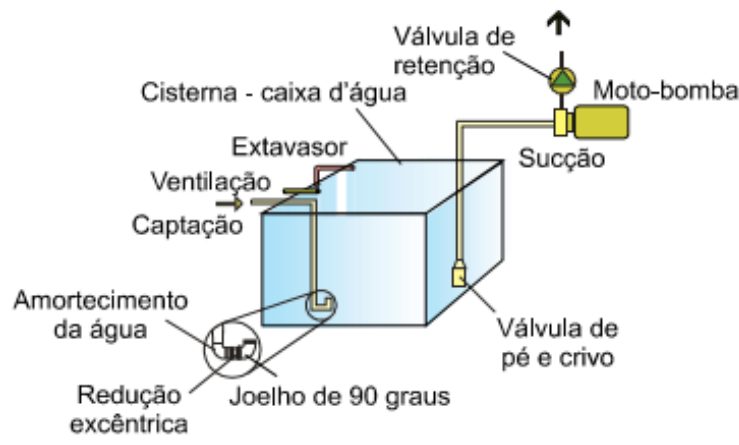

Figura 03 - Modelo do Reservatório usado no sistema de captação e armazenamento. Fonte: ANA (2002) citado por Manual FIESP/CIESP (2006).

O reservatório superior será alimentado através de um sistema motobomba. Entre o reservatório superior de água da chuva e o reservatório de água potável deverá existir um sistema de "by pass" que suprirá a falta de água da chuva com água potável.

\subsubsection{Reservatório para reúso de água.}

Os reservatórios para reúso terão volumes relacionados com o volume de esgoto secundário (água de banho, lavatório, máquina de lavar roupas e água de fazer a barba) gerado em ambas as residências. Estes volumes serão constatados através de levantamento feito no local do consumo de água. Em cada residência existirá dois 
reservatórios: um inferior implantado para o armazenamento de água, e um superior apenas para distribuição do consumo. O reservatório inferior será de fibra de vidro e enterrado no terreno. Antes chegar ao reservatório, o esgoto secundário passará por uma caixa de remoção de areia para a retenção de seus resíduos, e por um sistema de tratamento com plantas denominado de Zona de Raízes. Após o armazenamento da água já com o tratamento adequado, ela será conduzida até o reservatório superior através de um sistema motobomba e em seguida irá alimentar os pontos de uso.

\section{RESULTADOS}

Para o projeto apresentado por Oliveira (2005) em que se realiza a captação, armazenamento e a distribuição das águas pluviais e de reúso, apresentou-se um levantamento dos usos finais dessa água no município de Palhoça. A partir da determinação destes usos finais, pode-se determinar o volume de água necessário para o aproveitamento da água de chuva e o volume de esgoto secundário disponível para seu reúso. Após determinar estes volumes, dimensiona-se os sistemas para a água de chuva e para o reúso de água cinza, e então é realizada a análise econômica para a determinação da viabilidade dos sistemas implantados.

\subsection{PONTOS DE MAIORES CONSUMOS NA RESIDÊNCIA 01}

Após a correção feito através dos métodos de sensibilidade, o local onde se apresentou maior consumo de água foi o chuveiro com $32,8 \%$ do consumo total da residência, seguido pelo vaso sanitário com $30,4 \%$ e a torneira da cozinha com $28,0 \%$, conforme Tabela 01.

Tabela 01 - Descrição dos consumos de água nos pontos da residência 01

\begin{tabular}{|c|c|c|c|c|c|}
\hline \multirow{2}{*}{ Aparelho } & \multicolumn{4}{|c|}{ Consumo (litros) } & \multirow[b]{2}{*}{$\%$} \\
\hline & $\mathbf{H}_{1}$ & $\mathbf{M}$ & $\mathbf{H}_{2}$ & Total & \\
\hline Chuveiro & 1528,9 & 1662,6 & 2092,8 & 5284,3 & 32,8 \\
\hline Lavatório & 92,8 & 132,1 & 73,8 & 298,7 & 1,9 \\
\hline Vaso Sanitário & 1465,1 & 2289,6 & 1138,6 & 4893,2 & 30,4 \\
\hline Barba & 75,6 & - & 55,2 & 130,8 & 0,8 \\
\hline Máquina Lavar Roupa & 333,3 & 333,3 & 333,3 & 1000,0 & 6,2 \\
\hline Torneira Cozinha & 1505,0 & 1505,0 & 1505,0 & 4515,0 & 28,0 \\
\hline TOTAL & & & & 16122,0 & 100,0 \\
\hline
\end{tabular}

Fonte: Oliveira,2005 


\subsection{PONTOS DE MAIORES CONSUMOS NA RESIDÊNCIA 02}

Na residência 02, após a correção, o maior consumo também foi constatado no chuveiro, com $45,6 \%$ do consumo total da residência, seguido pelo vaso sanitário com $25,6 \%$ e a pia da cozinha com 13,5\%, conforme apresentada na Tabela 02.

Tabela 02 - Descrição dos consumos de água nos pontos da residência 02

\begin{tabular}{lcccc}
\hline \multirow{2}{*}{ Aparelho } & \multicolumn{3}{c}{ Consumo (litros) } & \\
\cline { 2 - 4 } \multicolumn{1}{c}{ M } & $\mathbf{H}$ & Total & $\%$ \\
\hline Chuveiro & 1339,2 & 1762,8 & 3102,0 & 45,6 \\
Lavatório & 112,0 & 66,2 & 178,3 & 2,6 \\
Vaso Sanitário & 986,7 & 755,5 & 1742,2 & 25,6 \\
Barba & - & 300,0 & 300,0 & 4,4 \\
Máquina Lavar Roupa & 280,0 & 280,0 & 560,0 & 8,2 \\
Torneira Cozinha & 460,8 & 460,8 & 921,6 & 13,5 \\
\hline TOTAL & & & $\mathbf{6 8 0 4 , 0}$ & $\mathbf{1 0 0 , 0}$ \\
\hline
\end{tabular}

Fonte: Oliveira,2005

\subsection{USOS FINAIS PARA O APROVEITAMENTO DA ÁGUA DE CHUVA E REÚSO DE ÁGUA}

Para se determinar o volume diário disponível para o reúso de água e o volume diário necessário para o aproveitamento da água de chuva é obtido através dos usos finais de água após a correção realizada no consumo estimado. Nas Tabelas 03 e 04 observa-se a quantidade de água usada para o reúso, e também a quantidade necessária para o abastecimento através do reúso e o volume necessário para o aproveitamento da água pluvial. A quantidade necessária de água disponível para usar como reúso foi obtida do consumo no chuveiro, lavatório, água usada para fazer a barba e na máquina de lavar roupas, totalizando, para a residência 01, aproximadamente 240 litros, o que equivale a $41,9 \%$ do consumo total da residência. Com a água de reúso pode-se abastecer somente o vaso sanitário, havendo uma necessidade diária de 175,0 litros, cerca de $30 \%$ do consumo da residência. Logo, tem-se água disponível suficiente para abastecer o vaso sanitário. Utilizando a água de chuva, pode-se abastecer o vaso sanitário e a máquina de lavar roupa. $\mathrm{Na}$ residência 01 , há uma necessidade diária de 210,5 litros, cerca de $36,6 \%$ do consumo total da residência. 
Tabela 03 - Consumo para reúso e aproveitamento da água de chuva na residência 01.

\begin{tabular}{lccc|ccc|ccc}
\hline \multirow{4}{*}{ Aparelhos } & \multicolumn{10}{c}{ Consumo } \\
\cline { 2 - 10 } & \multicolumn{2}{c|}{ Reúso - Disponível } & \multicolumn{2}{c|}{ Reúso - Necessário } & \multicolumn{3}{c}{ Água Chuva } \\
\cline { 2 - 11 } & $\begin{array}{l}\text { Diário } \\
\text { (litros) }\end{array}$ & $\begin{array}{c}\text { Mensal } \\
\text { (litros) }\end{array}$ & $\%$ & $\begin{array}{l}\text { Diário } \\
\text { (litros) }\end{array}$ & $\begin{array}{c}\text { Mensal } \\
\text { (litros) }\end{array}$ & $\%$ & $\begin{array}{l}\text { Diário } \\
\text { (litros) }\end{array}$ & $\begin{array}{c}\text { Mensal } \\
\text { (litros) }\end{array}$ & $\%$ \\
\hline Chuveiro & 188,7 & 5284,3 & 32,8 & - & - & - & - & - & - \\
Lavatório & 10,7 & 298,7 & 1,9 & - & - & - & - & - & - \\
Vaso Sanitário & - & - & - & 174,8 & 4893,3 & 30,4 & 174,8 & 4893,3 & 30,4 \\
Barba & 4,7 & 130,8 & 0,8 & - & - & - & - & - & - \\
Máquina Lavar Roupa & 35,7 & 1000,0 & 6,2 & - & - & - & 35,7 & 1000,0 & 6,2 \\
\hline TOTAL & $\mathbf{2 3 9 , 8}$ & $\mathbf{6 7 1 3 , 8}$ & $\mathbf{4 1 , 9}$ & $\mathbf{1 7 4 , 8}$ & $\mathbf{4 8 9 3 , 3}$ & $\mathbf{3 0 , 4}$ & $\mathbf{2 1 0 , 5}$ & $\mathbf{5 8 9 3 , 3}$ & $\mathbf{3 6 , 6}$ \\
\hline
\end{tabular}

Fonte: Oliveira,2005

Tabela 04 - Consumo para reúso e aproveitamento da água de chuva na residência 02.

\begin{tabular}{|c|c|c|c|c|c|c|c|c|c|}
\hline \multirow{3}{*}{ Aparelhos } & \multicolumn{9}{|c|}{ Consumo } \\
\hline & \multicolumn{3}{|c|}{ Reúso - Disponível } & \multicolumn{3}{|c|}{ Reúso - Necessário } & \multicolumn{3}{|c|}{ Água Chuva } \\
\hline & $\begin{array}{l}\text { Diário } \\
\text { (litros) }\end{array}$ & $\begin{array}{c}\text { Mensal } \\
\text { (litros) }\end{array}$ & $\%$ & $\begin{array}{l}\text { Diário } \\
\text { (litros) }\end{array}$ & $\begin{array}{c}\text { Mensal } \\
\text { (litros) }\end{array}$ & $\%$ & \begin{tabular}{|l} 
Diário \\
(litros)
\end{tabular} & $\begin{array}{c}\text { Mensal } \\
\text { (litros) }\end{array}$ & $\%$ \\
\hline Chuveiro & 110,8 & 3102,0 & 44,6 & - & - & - & - & - & - \\
\hline Lavatório & 6,4 & 178,3 & 2,6 & - & - & - & - & - & - \\
\hline Vaso Sanitário & - & - & - & 62,2 & 1742,2 & 25,6 & 62,2 & 1742,2 & 25,6 \\
\hline Barba & 20,0 & 300,0 & 4,4 & - & - & - & - & - & - \\
\hline Máquina Lavar Roupa & 32,9 & 560,0 & 8,2 & - & - & - & 32,9 & 560,0 & 8,2 \\
\hline TOTAL & 170,1 & 4140,3 & 60,8 & 62,2 & 1742,2 & 25,6 & 95,1 & 2302,2 & 33,8 \\
\hline
\end{tabular}

Fonte: Oliveira,2005

\subsection{ECONOMIA FINAL COM A CAPTAÇÃO, ARMAZENAMENTO E TRATAMENTO DA ÁGUA DA CHUVA E A DE REÚSO}

A Tabela 05, mostra as economias com água potável, referente a utilização do sistema de aproveitamento da água proveniente da chuva, da implantação do sistema de água de reúso e da implantação da água de chuva e reúso juntos, nas residências 01 e 02, em moeda corrente (reais) e em porcentagem.

$\mathrm{Na}$ residência 01 , tem-se uma economia anual com água potável de 35,5\% devido a implantação do sistema de aproveitamento da água de chuva, e cerca de 30,4\% com a utilização do sistema de reúso. A implantação do conjunto água de chuva e reúso, produziu uma economia com água potável de $36,4 \%$. 
Para a residência 02, implantando-se um sistema de aproveitamento da água de chuva, obteve-se uma economia com água potável de 33,6\%, e com a implantação do reúso, $25,6 \%$. A economia total com as duas formas de captação, foi de $33,8 \%$.

Tabela 05 - Economia Anual nas residências 1 e 2.

\begin{tabular}{lcccc}
\hline \multirow{2}{*}{\multicolumn{1}{c}{ Economia }} & \multicolumn{4}{c}{ Economia } \\
\cline { 2 - 5 } & \multicolumn{2}{c}{ Residência l } & \multicolumn{3}{c}{ Residência 2 } \\
\cline { 2 - 5 } & $\mathbf{R} \$$ & \% & R & \% \\
\hline Economia anual - água de chuva & 117,10 & 35,5 & 46,75 & 33,6 \\
Economia anual - reúso de água & 100,05 & 30,4 & 35,60 & 25,6 \\
Economia anual - água de chuva + reúso & 119,84 & 36,4 & 47,01 & 33,8 \\
\hline
\end{tabular}

Fonte: Oliveira,2005

\section{DISCUSSÃO}

Para o projeto apresentado na cidade de Palhoça abordado nesse artigo, o sistema usou componentes simples que atenderam todas as necessidades básicas e que além de ser um método fácil, pode gerar economia para os moradores onde 0 investimento inicial foi baixo e o retorno aconteceu em um curto espaço de tempo. A pesquisa ainda compara o mesmo método aplicado em duas unidades diferentes, o que visa estabelecer os métodos construtivos e sua contribuição para a coleta e armazenamento de água para o reúso.

Outros autores estabelecem sistemas diferentes de captação e tratamento da água cinza e pluvial, onde a economia varia conforme os investimentos estabelecidos por cada modelo e também conforme a eficiência do sistema.

Segundo o trabalho de Silveira (2008), a "Linha Europa", baseada em uma pesquisa alemã de tratamento de água de chuva, compreende em sistemas que irão suprir o uso interno e externo, atendendo também a áreas de maior captação. É ideal para residências que ainda estão na fase de construção, pois permite uma maior integração entre os sistemas de água potável e pluvial. Esse método segundo a pesquisadora irá utilizar uma bomba, além de outros acessórios, como freio d'água (para reduzir o turbilhonamento na cisterna), filtro flutuante para permitir uma maior qualidade da água captada e multisifão para não deixar que insetos entrem no sistema. O dimensionamento do reservatório para o armazenamento será o mesmo que o abordado no trabalho realizado na cidade de Palhoça, onde é definido através da previsão de consumo, base de captação e o tempo de estiagem para o local. Pode- 
se ainda ligar o sistema da água da chuva com a água da rede pública de abastecimento para que nos momentos de falta d'água a integração entre os dois sistemas garanta a qualidade e o abastecimento, conforme Figura 04.

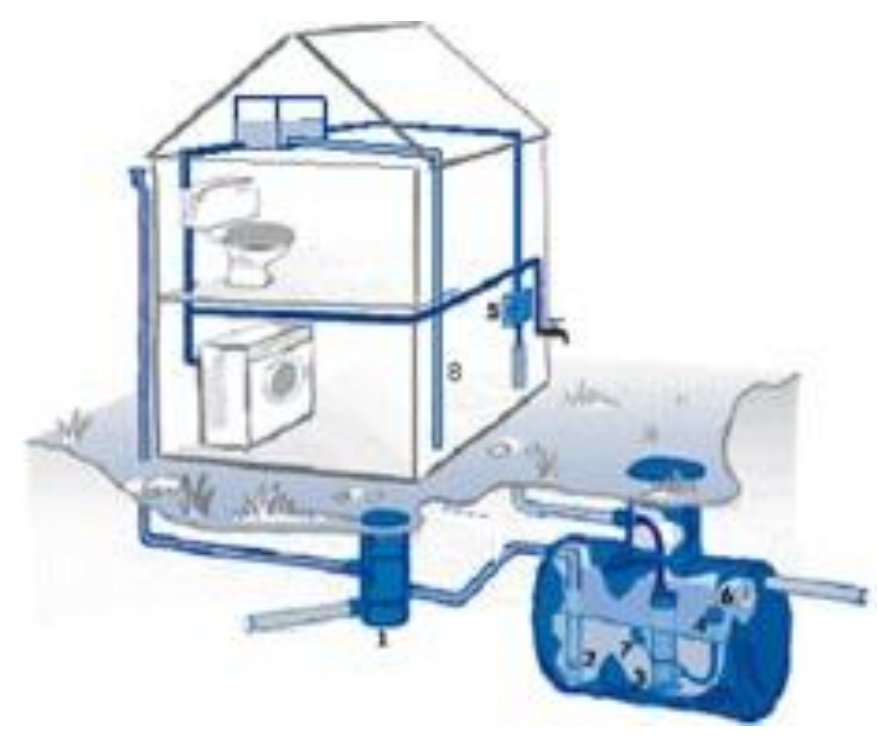

1.Filtro tipo vortex

2. Freio d'água

3. Bomba submersível

4. Filtro flutuante

5. Central de controle/ interligação com rede pública

6. Multisifão

7. Bóia de nível

8. Alimentação dos Pontos de Consumo a partir da Caixa d'água superior

Figura 04: Modelo da Linha Europa abordado pela pela mestranda Bruna Quick da Silveira Fonte: AQUASTOCK,2008.

Os dois sistemas confrontados são eficientes, mas usam maneiras diferentes de captar, tratar e distribuir a água coletada, onde cada método possui sua particularidade. A eficiência de ambos é satisfatória o que torna os dois esquemas usuais e econômicos, tendo como fator determinante para escolher o mais adequado o investimento inicial que cada um irá demandar, sendo o usado na cidade de Palhoça o método mais simples, que acaba exigindo um investimento inicial menor que o apresentado pela mestranda, nomeado como sistema "Linha Europa".

\section{CONCLUSÃO}

A partir do objetivo desse artigo, pode-se perceber que o interesse da sociedade é pequeno quando o assunto em pauta é a instalação de um sistema capaz de 
reutilizar a água que antes era descartada. Isso acontece por existir certo preconceito com a reutilização de água advinda dos efluentes domésticos e também pelo maior risco de contaminações associadas ao sistema de manutenções que possam promover danos à saúde dos usuários diretos ou indiretos do sistema. Um método de reúso adequado e operado de forma consciente aumenta a eficiência e reduz qualquer tipo de contaminações que possam ocorrer por parte do operador ou do sistema como um todo.

O modelo de captação apresentado nesse trabalho ou em qualquer outro disponibilizado no mundo requer um custo inicial de instalação muito alto, porém a longo prazo deve-se ter economia no volume de água usado na residência, bem como na qualidade da água que é recebida, pois ao se tratar e reutilizar a água que antes voltava para a natureza haverá a preservação da qualidade desse bem que, além de finito, é primordial para o bem-estar e para a qualidade de vida humana.

\section{REFERÊNCIAS}

ABNT - Associação Brasileira de Normas Técnicas. NBR 10844 - Instalações Prediais de Águas Pluviais. Rio de Janeiro (1989).

ABNT Associação Brasileira de Normas Técnicas. NBR 5626 - Instalações Prediais de Água Fria. Rio de Janeiro (1998).

ANA - Agência Nacional de Águas. A Evolução da Gestão dos Recursos Hídricos no Brasil / The Evolution of Water Resources Management in Brazil. Brasília; ANA, 2002.

AQUASTOCK - Água da Chuva. Sistema de Reaproveitamento da Água da Chuva. Disponível em: <http://www.engeplasonline.com.br> Acesso em: 21/08/2008

BIO: Revista Brasileira de Saneamento e Meio Ambiente. Água: o ouro azul do século XXI. Rio de Janeiro, RJ, v.11, n. 21, jan./mar. 2002

BIO: Revista Brasileira de Saneamento e Meio ambiente. Centronetwork. Rio de Janeiro, $n^{\circ}$ 21. Ano XI. 2002. p.50

BRAGA, BENEDITO et al. Introdução à Engenharia Ambiental $O$ desafio do desenvolvimento sustentável. 2 $2^{\underline{a}}$ edição. São Paulo: Pearson Prentice Hall, 2005.

CAUBET, Christian Guy. A água doce nas relações internacionais, ano 2006. 
da Universidade de Passo Fundo (RS), 2005. Disponível: <http//www.usp.br>. Acesso em 12/11/2016.

GONÇALVES, R. F. (Coord.). Conservação de água e energia em sistemas prediais e públicos de abastecimento de água. Rio de Janeiro: ABES, 2009

HESPANHOL, I. Potencial de Reúso de Água no Brasil: Agricultura, Indústria, Municípios, Recarga de Aquíferos. Recursos Hídricos: APRH, Portugal, v. 23, n.2, p.43-65, nov. 2002.

LIBÂNIO, M. Fundamentos de qualidade e tratamento de água, $3^{\circ}$ edição Campinas: Átomo, 2010.

MARIANE, Aline -Construtoras adotam sistemas de reúso e aproveitamento de água de chuva, além de métodos de construção seca, para contornar falta de água nas obras. Disponível em: http://construcaomercado.pini.com.br/negociosincorporacao-construcao/161/artigo333851-1.aspx >Dez,2014. Acesso em: 12 Dez.2016.

MAY, Simone. Conservação e Reúso de Água em Edifícios: Reúso De Águas Cinzas e Aproveitamento De Águas Pluviais Para Consumo Não Potável. Escola Politécnica da Universidade de São Paulo (USP),2009.

MAYOK, SIMONE. Caracterização, tratamento e reuso de águas cinzas e aproveitamento de águas pluviais em edificações. São Paulo, junho, 2009.

MIERZWA, J.C; VERAS,L.R; SILVA,M.C. Avaliação do Desempenho de Membrana de Ultrafiltração para Tratamento de Água Potável. VIII Seminário Ibero-Americano. São Paulo: 2005.

OLIVEIRA, N. M.; SILVA, M. P. da.; CARNEIRO, V. A. Reúso da água: um novo paradigma de sustentabilidade. Revista Gestão e Desenvolvimento em ContextoGEDECON Edição Especial - Porangatu, v.2, n.1, p.146-157, jan. /jul. 2013.

OLIVEIRA, Sulayre Mengotti de. Aproveitamento da água da chuva e reúso de água em residências unifamiliares: estudo de caso em Palhoça - SC, junho de 2005.

OPAS (2001) Água e Saúde.Relatório.www.opas.org.br/sistema/fotos/agua.pdf. $<$ Acessado em abril de 2017>

PALHOÇA, Prefeitura Municipal de Palhoça. Disponível em: http://palhoça.sc.gov.br, acessado em novembro de 2004.

PROSAB, Uso Racional da Água em Edificações-Ricardo Franci Gonçalves (Coord.). Rio de Janeiro : ABES, 2006

SETTI, A. A. A Necessidade do Uso Sustentável dos Recursos Hídricos. IBAMA, Brasília, 1994. 
SICKERMANN, Jack M. Gerenciamento Sustentável das Águas de Chuva: imprescindível para o futuro das grandes cidades do Brasil. Piauí, 2005. 9p.

SILVEIRA, Bruna Quick da. REUSO DA ÁGUA PLUVIAL EM EDIFICAÇÕES RESIDENCIAIS, janeiro de 2008.

TOMAZ, P. Economia de água para empresas e residências: um estudo atualizado sobre o uso racional da água. $2^{\circ}$ Edição. São Paulo: Navegar Editora, 2005.

VESENTINI, J. W. Brasil, sociedade e espaço. 7. ed. São Paulo: Ática, 1999. ZAMPIERON, Sônia Lúcia Modesto; VIEIRA, João Luiz de Abreu. "Poluição da Água". Disponível em: <http://educar.sc.usp.br/biologia/textos/m_a_txt5.html> 